Journal of

Dentistry and Oral Health

\title{
Tridax Procumbens Flavonoids Stimulated Synergistic Effects on BMP-2-Induced Bone Regeneration in Critical-Sized of Calvarial Defect
}

\author{
Md. Abdullah Al Mamun ${ }^{1,}$, Md. Muzammal Haque Asim¹, Md. Ali Zaber Sahin ${ }^{1}$, M. Masihul Alam ${ }^{2}$ and \\ Md. Abdul Alim Al-Bari ${ }^{3}$ \\ ${ }^{1}$ Department of Genetic Engineering and Biotechnology, Shahjalal University of Science and Technology, Sylhet-3114, Bangla- \\ desh \\ ${ }^{2}$ Department of Applied Nutrition and Food Technology, Islami University, Kustia 7003, Bangladesh \\ ${ }^{3}$ Department of Pharmacy, University of Rajshahi, Rajshahi-6205, Bangladesh
}

${ }^{\star}$ Corresponding author: Md. Abdullah Al Mamun, Professor, Department of Genetic Engineering and Biotechnology, Shahjalal University of Science and Technology, Sylhet-3114, Bangladesh; Tel:+88-01714516919; Fax: +88-821-715257; E-mail: mssohel@yahoo.com

Received Date: July 08, 2019 Accepted Date: August 17, 2019 Published Date: August 19, 2019

Citation: Abdullah Al Mamun (2019) Tridax Procumbens Flavonoids Stimulated Synergistic Effects on BMP-2-Induced Bone Regeneration in Critical-Sized of Calvarial Defect. J Dent Oral Health 6: 1-8.

\begin{abstract}
Bone morphogenetic protein (BMP)-2 is widely used as an effective growth factor to promote bone regeneration for improving bone repair. The ability of BMP-2 to induce bone regeneration relies heavily on requiring large amounts for its short half-life, thereby causing side effects such as cancer and inflammation. Combination therapies using BMP-2 with bioactive agents that can reduce the required amount of BMP-2 have been developed. Recently, we found that Tridax procumbens flavonoids (TPF) stimulated osteoblast differentiation which was demonstrated by increasing of alkaline phosphatase, osteocalcin and type 1 collagen. This study aimed to assess whether TPF elicits synergistic effects on BMP-2 induced local bone regeneration. A calvarial defect model was employed in C57BL/6 male mice. TPF combination with BMP-2 was implanted on the defect sites. The mice were sacrificed on day 28 after implantation. The radiographic and histomorphometric analyses were performed to assess the healing of the defects. The radiographic analyses of the defect sites showed that TPF with BMP-2 group led to higher bone regeneration compared to BMP-2 only group. Histomorphometric analyses showed that the bone regeneration parameters were significantly higher when TPF with BMP-2 was used. Our data suggest that TPF could enhance the stimulatory effects of BMP-2-induced bone regeneration in critical-sized defect of mice.
\end{abstract}

Keywords: BMP-2, Bone regeneration, Critical-sized defect, and Tridax procumbens Flavonoids.

(C)2019 The Authors. Published by the JScholar under the terms of the Creative Commons Attribution License http://creativecommons.org/licenses/ by/3.0/, which permits unrestricted use, provided the original author and source are credited. 


\section{Introduction}

Bone morphogenetic proteins (BMPs), which belong to the transforming growth factor (TGF)- $\beta$ superfamily, are essential for embryogenesis, chondrogenesis and skeletal development [1,2] which are responsible for fracture repair and regeneration of bone defects [3,4]. Among the BMPs, BMP-2 is one of the most potent inducible growth factor involved in bone formation in vivo [5]. Clinical trials of BMP-2 have demonstrated its role in accelerating bone regeneration during both fracture healing and spinal fusion [6,7]. However, the use of BMP-2 requires large amounts for its short half-life to form bone and it cannot maintain marked osteoinductive effect in vivo [8-10]. Furthermore, it is difficult to produce BMP-2 in mass and then put them into broad application in medicine $[11,12]$. Also, recombinant BMP-2 (RH-BMP-2) is expensive and treatment with high doses is associated with side effects $[13,14]$. The recent evidence showed that BMP-2 has the potential to cause cancer and retropharyngeal swelling is induced by high doses of rh-BMP-2 [15-17]. Therefore, a reduction in the amount of BMP-2 therapy is necessary to reduce its adverse effects and it is necessary to develop an appropriate enhancer of anabolic agents, which can directly stimulate bone formation or at least accelerate BMP-2induced bone formation [18]. Previous studies have shown that natural bioactive compounds, could help in recover fracture as well as bone loss $[19,20]$ and have been found to decrease urinary excretion of calcium and phosphate, increase osteoblast activity, decrease osteoclast activity, and protect against the loss of trabecular thickness either alone or in combination $[21,22]$. Due to their lack of toxicity and side effects, they are considered to be safer than the chemical synthetic drugs replacement therapy as preventive measures against various diseases including osteoporosis and osteoarthritis [23,24]. Tridax procumbens extracts are known for their traditional medicinal properties to increase osteogenic properties and osteoblasts differentiation in mesenchymal stem cells [25-27]. Previously, we showed the inhibitory effects of TPF on osteoclast differentiation and bone resorption. TPF significantly suppressed the receptor activator of nuclear factor kappa-B ligand (RANKL)-induced differentiation of osteoclasts and formation of pits in primary osteoclasts [28]. We also showed that TPF decreased the expression of osteoclast differentiation-related genes including tartrate-resistant acid phosphatase (Trap), Cathepsin K, matrix metalloproteinases (Mmp)-9 and Mmp-13 in primary osteoclasts [28]. In other studies, reported that TPF promoted osteoblasts differentiation and bone formation in a dose-dependent manner demonstrated by up-regulation of ALP [29,30]. TPF also significantly induced higher bone mass investigated by bone mineral density (BMD) and bone mineral content (BMC) was increased in TPF-treated low calcium diet mice [30]. In the current study, we demonstrated that the combined of TPF with BMP-2 induced higher bone formation activity and bone mass compared to BMP-2 only in a murine calvarial defect model.

\section{Materials and Methods}

\section{Reagents}

BMP-2 was purchased from Pfizer Inc. (New York, USA). Type 1 collagen was purchased from Zimmer Dental (Carlsbad, CA, USA). The biopsy punch (3.5 millimeters, used to make the calvarial defect) was purchased from Kai industries (Gifu, Japan).

\section{Selection of Tridax procumbens}

The Tridax procumbens plants are widely available through over the country (Bangladesh). The selection of samples and collection of flavonoids were described elsewhere [28,29] with some modifications. Briefly, it was collected the samples from the northeast part (Sylhet region) of Bangladesh under the close supervision of principal investigator, a voucher specimen (Ref. GEB09032016/5) was submitted to the Plant Biotechnology Laboratory, Department of Genetic Engineering and Biotechnology, Shahjalal University of Science and Technology, Sylhet-3114, Bangladesh and processed for sample preparation.

\section{Sample preparation}

Different plant parts of Tridax procumbens (root, stem, leaf, and flowers) were separately shade dried, finely powdered using a sterile blender, and subjected to extraction of flavonoids as described elsewhere $[28,29]$ with some modifications. Briefly, two hundred grams of each finely powdered sample was Soxhlet extracted with $80 \%$ hot methanol $(1000 \mathrm{ml})$ on a water bath for $24 \mathrm{~h}$ and filtered. The filtrate was re-extracted successively with petroleum-ether, ethyl-ether and ethyl-acetate using separating funnel. Petroleum-ether fractions were discarded as being rich in fatty substances, whereas ethyl-ether and ethyl-acetate fractions were analyzed for free and bound flavonoids, respectively. The ethyl-acetate fraction which contained sugar bounded flavonoid does not function in the biological system. The ethyl-acetate fraction (bounded flavonoid) was hydrolyzed by refluxing with $7 \% \mathrm{H}_{2} \mathrm{SO}_{4}$ for $2 \mathrm{~h}$ for removal of bounded sugars from the flavonoid. The resulting mixture was collected from separating funnel. The extract thus obtained was washed with distilled water to neutrality and dried for further use $[28,29]$. In this study, we used bound free flavonoid for osteoblast differentiation and bone formation. 
Total flavonoids determination

Total flavonoids content of each extract was determined by aluminum chloride as described elsewhere [28,29] with some modifications. Briefly, plant extracts $(0.5 \mathrm{ml}$ of $1: 10 \mathrm{~g} / \mathrm{ml})$ were separately mixed with $1.5 \mathrm{ml}$ of methanol, $0.1 \mathrm{ml}$ of $10 \%$ aluminum chloride, $0.1 \mathrm{ml}$ of $1 \mathrm{M}$ potassium acetate and $2.8 \mathrm{ml}$ of distilled water. It remained at room temperature for $30 \mathrm{~min}$. The absorbance of the reaction mixture was measured at $415 \mathrm{~nm}$ with a spectrophotometer, and quercetin was used as a standard for the calibration curve. Total flavonoids values are expressed in terms of mg equal quercetin in $1 \mathrm{~g}$ of powder.

\section{Extraction of chitin from shrimp shell}

Chitin was obtained from shrimp shell as described elsewhere [31]. In brief, removal of protein, $40 \% \mathrm{NaOH}(\mathrm{w} / \mathrm{v})$ was added into shrimp shell and the deproteination process was led for 72 hours. After deproteination, the shells were washed with distilled water. Then removal of calcium from these shells was treated with $4 \%$ concentrated of $\mathrm{HCl}$ and the demineralization time was 20-24 hours and then after demineralization, the shells were washed with distilled water and dried. These deproteinated and decalcified shells are chitin.

\section{Conversion of Chitin to Chitosan}

To produce chitosan, dried deproteinated and decalcified chitins were mixed with distriled water. Removal of acetyl groups from distilled water mixed chitin was used $20 \mathrm{M} \mathrm{NaOH}$ solution and stirred. The process was carried out for 48 hours. After deactivation, chitosan flakes were washed, squeezed and dried in a forced-air oven at $60-70^{\circ} \mathrm{C}[31]$.

\section{Preparation of type 1 collagen/chitosan scaffold}

Type 1 collagen and chitosan was dissolved in $0.5 \mathrm{M}$ acetic acid solution to prepare a $0.5 \%(\mathrm{w} / \mathrm{v})$ solution, respectively. The chitosan solution was slowly dropped into type 1 collagen suspension in the ratio of 9:1 (type 1 collagen: chitosan) and homogenized to obtain collagen/chitosan blend. After deaerated under vacuum to remove entrapped air bubbles, the collagen/ chitosan blend was injected into the mould, frozen in 70\% ethanol bath at $-20{ }^{\circ} \mathrm{C}$ for $1 \mathrm{~h}$ and then lyophilized for $24 \mathrm{~h}$ to obtain collagen/chitosan scaffold.
Preparation of collagen/chitosan containing TPF with BMP-2 discs

Collagen/chitosan discs $(3.5 \mathrm{~mm}$ in diameter and $2 \mathrm{~mm}$ thick) were prepared using biopsy punches (Kai Industries, Gifu, Japan) from collagen/chitosan scaffold. $1 \mu \mathrm{g}$ of BMP-2 and $1 \mu \mathrm{g}$ of BMP-2 combined with $0.2 \mathrm{mg}$ of TPF $(20 \mathrm{mg} / \mathrm{kg}$ ) were added to the collagen/chitosan discs. After adding BMP-2 and TPF, the collagen/chitosan discs including carrier control (collagen/chitosan discs without adding any agents) were freeze-dried overnight.

\section{Animals}

C57BL/6 male mice were obtained from ICDDR,B (Dhaka, Bangladesh) and maintained in our animal care facilities as described elsewhere $[28,30]$. The experimental procedures were reviewed and approved by the Animal Care and Use Committee of Rajshahi University, Bangladesh.

\section{Preparation of the calvarial defect model}

A calvarial defect, 3.5 millimeters in diameter, was made on the left parietal bone using a biopsy punch. BMP-2, TPF with BMP-2 or vehicle incorporated in each carrier was put on the defect site of the calvariae. Double calcein injections were performed on days 18 and 25, and the mice were sacrificed on day 28 after implantation. Calvarial samples were fixed as described previously for the radiological and histological analyses [30].

\section{Radiographic analyses}

Soft X-ray photographs of calvariae were taken using a cabinet X-ray apparatus (type SRO-M50; Sofron, Tokyo, Japan). Three-dimensional (3D) reconstruction images of the calvariae were obtained by micro-focal computed tomography ( $\mu$-CT) (Scan Xmate-E090; Com scan, Yokohama, Japan). The bone mineral content (BMC) and bone mineral density (BMD) of the calvariae were measured using dual-energy X-ray absorptiometry (DXA) (DCS-600R, Aloka, Tokyo, Japan) [30].

\section{Histological preparation and bone histomorphometry}

Undecalcified methyl methacrylate (MMA) resin sections $(5 \mu \mathrm{m})$ were prepared as described elsewhere [30]. A standard bone histomorphometric analysis was performed by using an image analyzing system (KS400; Carl Zeiss, Jena, Germany) in the $1.05 \mathrm{~mm} \times 0.83 \mathrm{~mm}$ region of interest at the center of the regenerated site of the calvarial defect. Bone formation and mineralized tissue area were detected by using toluidine blue staining and von-Kossa staining methods [30]. 


\section{Statistical analysis}

We used analysis of variance with F-test flowed by SPSS. P values less than 0.05 were considered significant. The data are presented as mean \pm standard deviation values of independent replicates.

\section{Results}

\section{Effects of TPF on BMP-2 induced bone regeneration}

The calvarial defect model was used to clarify whether TPF could increase the effects on BMP-2 induced bone regeneration in vivo. The soft X-ray and $\mu$-CT images at the defect sites revealed that larger and thicker bone had appeared in the group that received TPF with BMP compared to BMP-2 only group (Figure $1 \mathrm{~A}, \mathrm{~B}$ ). To confirm these radiological observations, the BMC and BMD were measured by using DXA. Both the BMC and BMD were significantly higher in the group treated by TPF with BMP-2 compared to BMP-2 only group (Figure 1C, D).

Histological observations of the bones in the calvarial defect sites

Further, the regenerated bones of defect sites were clarified by the toluidine blue staining, were significantly larger in the group that received TPF with BMP-2 compared to BMP-2 only group (Figure 2 A, B). The bone histomorphometric analyses showed that the number of osteoblasts (N.Ob), osteoblast surface/bone surface (Ob.S/BS) and bone volume were significantly larger in the group that treated TPF with BMP- 2 compared to BMP- 2 only group (Figure 2C, D, E). There were no significant differences in osteoid per bone surface (OS/BS) among the groups received TPF with BMP-2 and BMP-2 only (Figure 2F).

\section{Effects on bone formation parameters in TPF treated mice}

The mineralized areas of the regenerated bones stained by the von-Kossa method were significantly larger in the group that received TPF with BMP-2 compared to BMP-2 only group (Figure $3 \mathrm{~A}, \mathrm{~B})$. The bone histomorphometric analyses showed that the bone volume/tissue volume (BV/TV), mineralizing surface/bone surface (MS/BS), mineral apposition rate (MAR), bone formation rate (BFR), which indicated the structural indexes of regenerated bones, were significantly larger in the group that received TPF with BMP-2 compared to BMP-2 only group (Figure 3C, D, E, F). The fluorescent images showed that the calcein-labeled surface was larger in the group that received TPF with BMP-2 compared to BMP-2 only group (Figure 4A, B). The bone histomorphometric analyses showed that the trabecular thickness (Tb.Th) and trabecular number (Tb.N) were significantly larger in the group that received TPF with BMP-2 compared to BMP2 only group (Figure 4C. D), whereas the trabecular separation (Th.Sp) was significantly decreased in the group that received TPF with BMP-2 compared to BMP-2 only group (Figure 4E).

Figure 1. The effects of TPF with BMP-2 on bone regeneration in a critical-sized murine calvarial defect model.

A

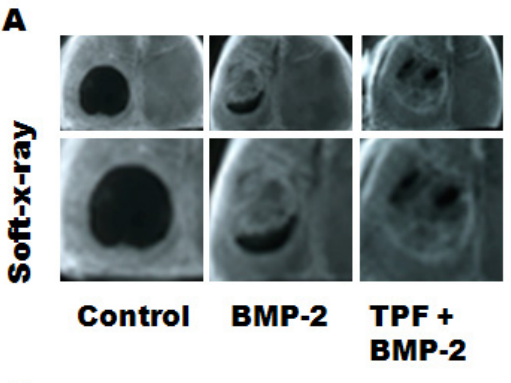

C (mg)

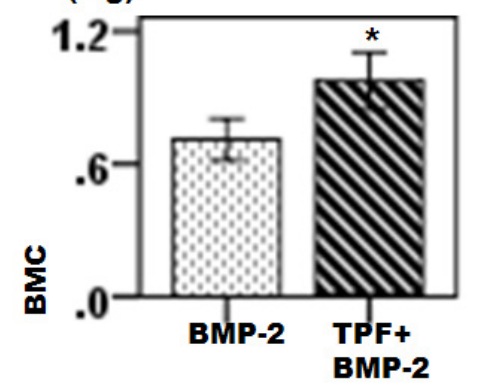

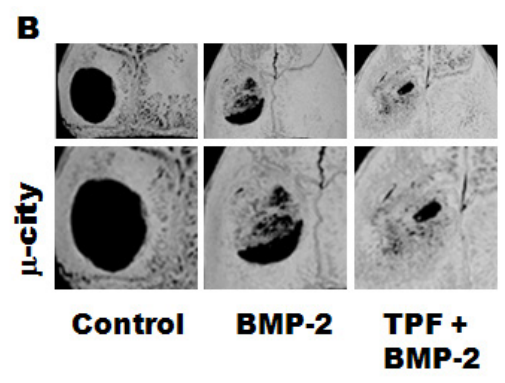

D $\left(\mathbf{m g} / \mathrm{cm}^{2}\right)$

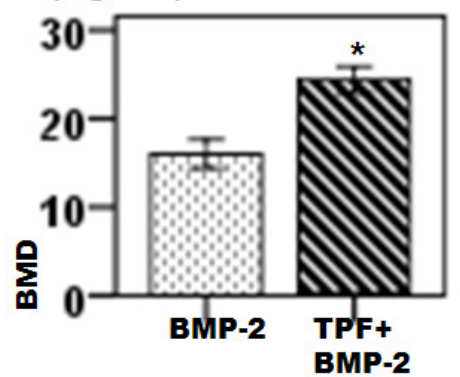

(A) Radiographic images of calvariae (Soft-x-ray). The effects of TPF on BMP-2-induced bone regeneration were investigated by using collagen/chitosan scaffold. The experimental groups are shown for carrier alone, carrier containing $1 \mu \mathrm{g}$ of BMP-2 and carrier containing $0.2 \mathrm{mg}$ of TPF with $1 \mu \mathrm{g}$ of BMP-2. The mice were sacrificed on day 28 after the implantation of the carrier discs. (B) $\mu \mathrm{CT}$ images of calvariae, (C) The BMC (bone mineral content) and (D) BMD (bone mineral density) were measured at the sites of the bone defect on the calvariae by using dual-energy absorptiometry. The data are expressed as the means \pm SD $(n=4)$ for each group. ${ }^{\star} \mathrm{p}<0.05$ vs TPF with BMP- 2 . 
Figure 2. Histological observations of the bone regeneration site in the calvarial defect model.
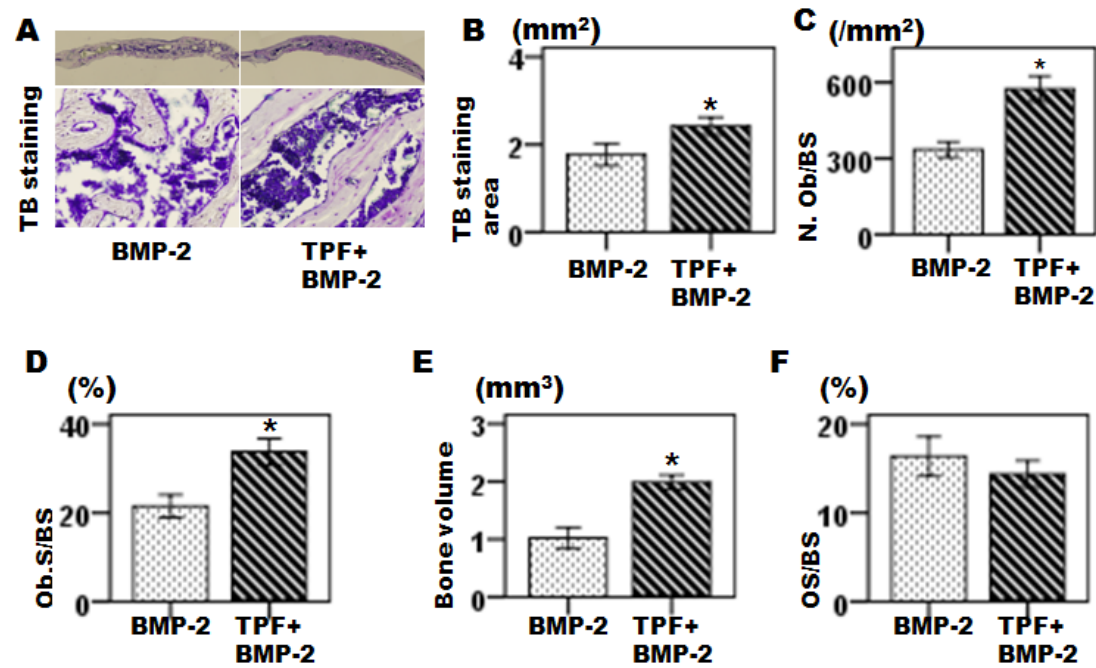

(A) The observations of undecalcified sections $(5 \mu \mathrm{m})$ stained by the toluidine blue, (B) Toludine blue strained area, (C) osteoblast number per bone surface (N.Ob/BS), (D) osteoblast surface per bone surface (Ob.S/BS), (E) Total bone volume, (F) osteoid per bone surface (OS/BS). The data are expressed as the means \pm SD $(n=4)$ for each group. ${ }^{\star} p<0.05$ vs TPF with BMP-2.

Figure 3. Histological observations of the bone regeneration sites in the calvarial defect model.

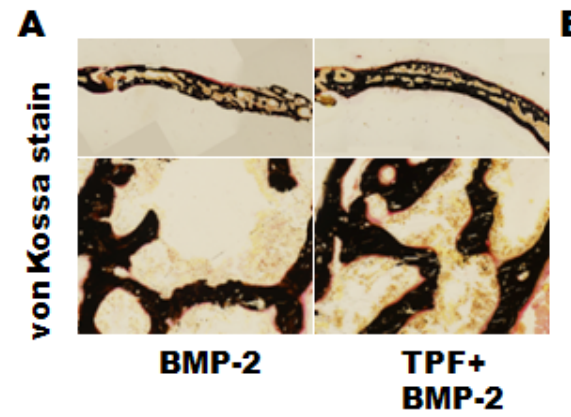

B

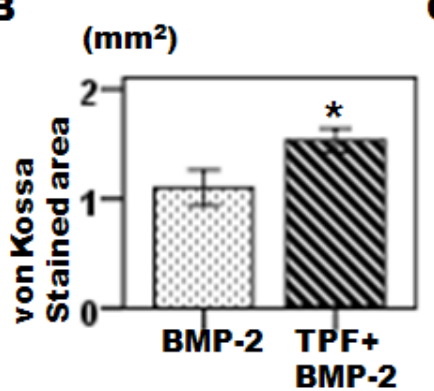

C $(\%)$

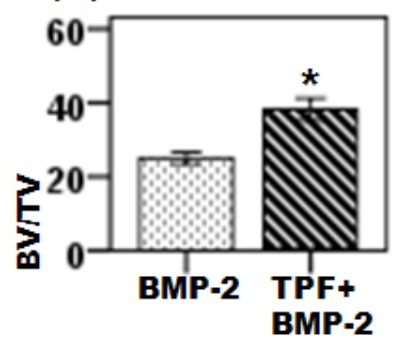

D (\%)

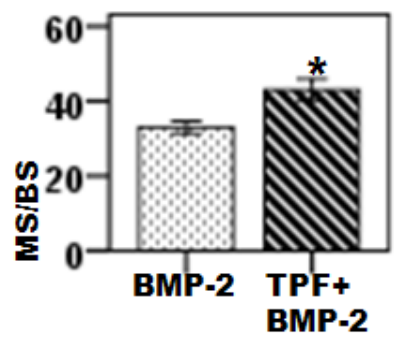

E $(\mu \mathrm{m} / \mathbf{d})$

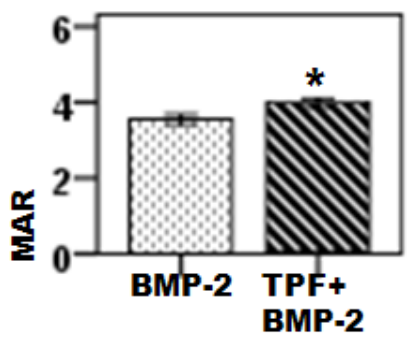

$\mathbf{F}\left(\mu \mathrm{m}^{3} / \mu \mathrm{m}^{2} / \mathrm{d}\right)$

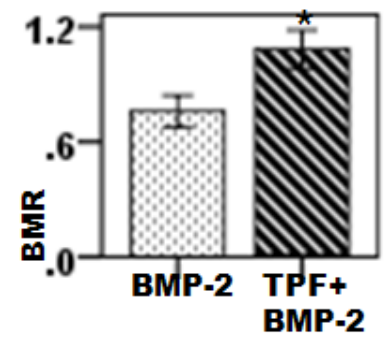

(A) undecalcified sections stained by von-Kossa, (B) von Kossa strained area, (C) bone volume/Tissue volume (BV/TV), (D) The mineralizing surface/bone surface (MS/BS), (E) mineral apposition rate (MAR), (F) bone formation rate (BFR). The data are expressed as the means $\pm \mathrm{SD}(\mathrm{n}=4)$ for each group. ${ }^{\star} \mathrm{p}<0.05$ vs TPF with BMP-2. 
Figure 4. The bone formation parameters at the defect sites of the calvariae.

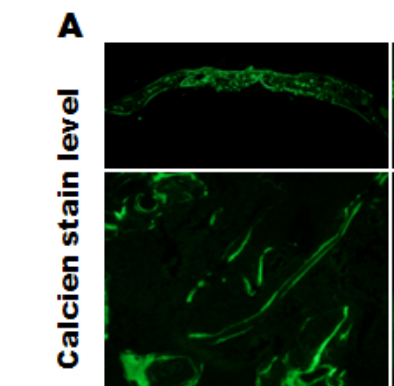

BMP-2

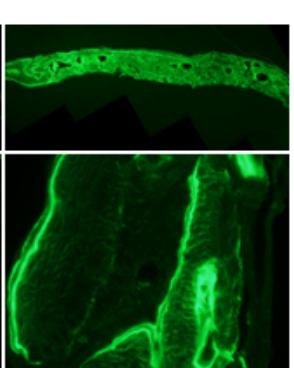

TPF+

$\mathbf{B}$

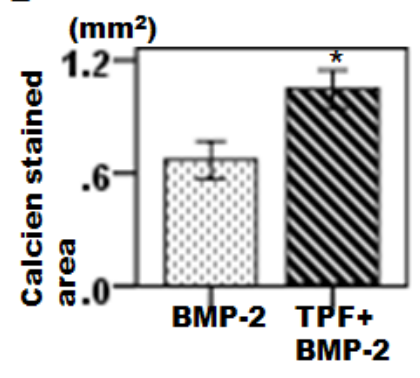

C

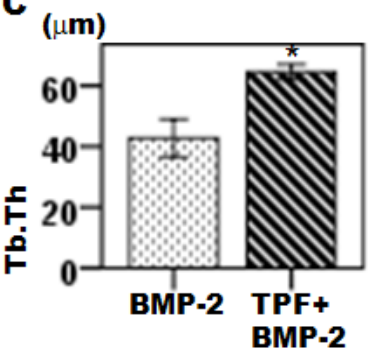

D $\left(\mathbf{m m}-\mathbf{1}^{-1}\right)$

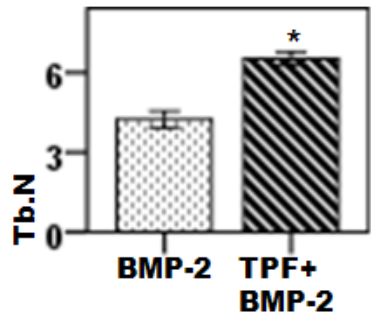

(A) Fluorescent images of the regenerated bone at the defect sites of the calvariae, (B) Fluorescent strained area, (C) trabecular thickness (Tb.Th), (D) trabecular number (Tb.N) and (E) trabecular separation (Tb.Sp). The data are expressed as the means \pm $\mathrm{SD}(\mathrm{n}=4)$ for each group. ${ }^{\star} \mathrm{p}<0.05 \mathrm{vs}$ TPF with BMP-2.

\section{Discussion}

As described previous, we have shown that the TPF induced osteoblast differentiation which was demonstrated by increasing alkaline phosphatase, osteocalcin, and type 1 collagen. TPF upregulated osteoblast differentiation-related genes, including Alp, osteocalcin, Type 1 collagen, BMP-2, BMP-4 and $B M P-7$ in primary osteoblasts $[29,30]$. TPF also increased osteoblast differentiation-related transcription factors, including osterix, and Runx2 in primary osteoblasts [29]. BMD and BMC were significantly increased in low calcium diet mice [30]. In this study, we investigated the effects of TPF on BMP-2-induced bone regeneration by using critical-sized murine calvarial defect. The combined of TPF with BMP-2 led to higher and thicker bone filling the whole bone defect area compared to BMP-2 only (Figure 1). The histomorphometric analyses revealed that higher bone formation activity was seen in the group treated TPF with BMP-2 compared to BMP-2 only (Figure 2,3), these results suggesting that TPF could be beneficial on BMP-2 induced bone regeneration. In this study, we did not administer TPF systemically, applied TPF with BMP-2 in the carrier to a critical-sized calvarial defect of mice for developing the future applications of bioprospecting natural drugs on local bone regeneration. This is the first study to demonstrate the local administration of TPF stimulated on BMP-2-induced bone formation. Several lines of evidence showed that numer- ous factors and agents, such as fibroblast growth factor (FGF)-2 [32], FGF-4 [33], prostaglandin $\mathrm{E}_{2}$ receptor agonist [34], TGF- $\beta 1$ [4] stimulated on BMP-2 induced bone formation. It was reported that at least $5 \mu \mathrm{g}$ of BMP-2 was optimal to induce bone regeneration [35]. A very little amount of $1 \mu \mathrm{g}$ of BMP-2 with TPF was used in the present study and radiographically observed that the defect sites almost recovered on day 28 after implantation compared to BMP-2 only group (Figure 1), suggesting that TPF might be a leading therapeutic candidate for developing anabolic agent, which can support on BMP-2 induced bone regeneration. The quantitative measurement of fluorescent-labeled areas of calcein showed that the amount of bone regeneration in the TPF with BMP-2 group could be much larger than that in the BMP-2 only group (Figure 4). On the other hand, the amount of bone volume and mineralization area might also increase in the TPF with BMP-2 administrated group (Figure 3) since the total osteoblast number and osteoclast number/bone surface was higher in the group that received TPF with BMP-2 compared to BMP-2 only group (Figure 2), suggesting that the TPF might be a potential accelerator on BMP-2 induced bone regeneration of this experiment. In this study, we could not directly measure the amount of TPF release to the local bone regeneration sites in vivo. However, we can speculate on the in vivo kinetics of the TPF release based on the bone formation parameters measured in this study. The newly formed bone continues to be remodeled, resulting in an ossicle. Therefore, the size of the bone is determined 
by the balance between the amount of bone formation and the amount of bone resorption during the experimental period. In our previous study, we showed that TPF significantly suppressed the RANKL-induced osteoclast differentiation and bone resoption [28]. The bone formation activities were measured by using a calcein-based histomorphometric technique. The calcein is absorbed by the bone formation surface at the time of injection, an increase of the MS/BS and BFR, the bone formation parameters, implies that there is an increase in the bone formation activities between the time points of calcein injections, i.e. from day 18 to day 25, suggesting that the osteoclast activity might be the same at the end of the experiment. Furthermore, it is generally difficult to determine the degree of osteoclast function to resorb bone by histological observation. Therefore, we could not evaluate the real balance between bone formation and bone resorption during the bone regeneration process in this study. Further studies are necessary to clarify the mechanism of the anabolic effects of TPF on bone formation.

\section{Conclusion}

The present study showed that TPF stimulated BMP-2induced local bone regeneration, even when a minimal amount of BMP-2 was applied. TPF might be a promising natural anabolic agent for supporting BMP induces bone regeneration.

\section{References}

1) Arora K, Levine MS, O'Connor MB (1994) The screw gene encodes a ubiquitously expressed member of the TGF- $\beta$ family required for specification of dorsal cell fates in the Drosophila embryo. Genes Dev 8:2588-2601.

2) Hogan BL (1996) Bone morphogenetic proteins: multifunctional regulators of vertebrate development. Genes Dev 10:15801594.

3) Tachi K, Takami M, Zhao B, Mochizuki A, Yamada A, Miyamoto Y (2010) Bone morphogenetic protein 2 enhances mouse osteoclast differentiation via increased levels of receptor activator of NF- $\kappa \mathrm{B}$ ligand expression in osteoblasts. Cell Tissue Res 342:213-220.

4) Tachi K, Takami M, Sato H, Mochizuki A, Zhao B, Miyamoto Y (2011) Enhancement of bone morphogenetic protein-2-induced ectopic bone formation by transforming growth factor- $\beta 1$. Tissue Eng Part A 17:597-606.

5) Cao X, Chen D (2005) The BMP signaling and in vivo bone formation. Gene 357:1-8.
6) Jones AL, Bucholz RW, Bosse MJ, Mirza SK, Lyon TR, Webb LX (2006) Recombinant human BMP-2, and allograft compared with autogenous bone graft for reconstruction of diaphyseal tibial fractures with cortical defects: A randomized, controlled trial. J Bone Joint Surg Am 88:1431-1441.

7) Villavicencio AT, Burneikiene S, Nelson EL, Bulsara KR, Favors M, Thramann J (2005) Safety of transforaminal lumbar interbody fusion and intervertebral recombinant human bone morphogenetic protein-2. J. Neurosurg Spine 3:436-443.

8) Yoshikawa H, Yoshioka K, Nakase T, Itoh K (2009). Stimulation of ectopic bone formation in response to BMP-2 by Rho kinase inhibitor: a pilot study. Clin Orthop Relat Res 467:30873095.

9) Boden SD (2005) The ABCs of BMPs. J. Orthopaedic Nursing 24(1): 49-52; quiz 53-4.

10) Malafaya PB, Silva GA, Baran ET (2002) Drug Delivery Therapies II: Strategies for Delivering Bone Regenerating Factors. J Current Opinion in Solid State and Materials Science 6: 297-312.

11) Wang EA, Rosen V, Cordes P, Hewick RM, Kriz MJ, et al. (1988) Purification and characterization of other distinct bone-inducing factors. Proc Natl Acad Sci U S A 85:9484-9488.

12) Carreon LY, Glassman SD, Djurasovic M, Campbell MJ, Puno RM, et al. (2009) RhBMP-2 versus iliac crest bone graft for lumbar spine fusion in patients over 60 years of age: a cost-utility study 34:238-2343.

13) Villavicencio AT, Burneikiene $S$, Nelson EL, Bulsara KR, Favors M, Thramann J (2005) Safety of transforaminal lumbar interbody fusion and intervertebral recombinant human bone morphogenetic protein-2. J Neurosurg Spine 3:436-43.

14) Shields LB, Raque GH, Glassman SD, Campbell M, Vitaz T, et al. (2006) Adverse effects associated with high-dose recombinant human bone morphogenetic protein-2 use in anterior cervical spine fusion. Spine (Phila Pa 1976) 31:542-547.

15) Feeley BT, Krenek L, Liu N, Hsu WK (2006) Overexpression of noggin inhibits BMP-mediated growth of osteolytic prostate cancer lesions. Bone 38: 154-166.

16) Woo EJ (2013) Adverse events after recombinant human BMP2 in nonspinal orthopedic procedures. Clin Orthop Relat Res 471: 1707-1711. 
17) Carreira AC, Lojudice FH, Halcsik E, Navarro RD (2014) Bone morphogenetic proteins: facts, challenges, and future perspectives. J Dent Res 93:335-345.

18) Gugala Z, Olmsted D (2003) Osteoinductive by ex vivo Adenovirus-mediated BMP-2 Delivery is Independent of Cell Type. J Gene Therapy 10: 1289-1295.

19) Myers G, Prince RL, Kerr DA, Devine A, Woodman RJ, et al. (2015) Tea and flavonoid intake predict osteoporotic fracture risk in elderly Australian women: a prospective study. Am J Clin Nutr 102:958-965.

20) Hashmi MA, Shah HS, Khan A, Farooq U, Iqbal J, et al. (2015) Anticancer and Alkaline Phosphatase Inhibitory Effects of Compounds Isolated from the Leaves of Olea ferruginea Royle. Rec. Nat. Prod 9:164-168.

21) Mitra C, Das D, Das AS, Preedy VR (2013) Black tea (Camellia sinensis) and bone loss protection. Academic Press 603-612.

22) Shen CL, Yeh JK, Cao JJ, Chyu MC, Wang JS (2011) Green tea and bone health: evidence from laboratory studies. Pharmacol Res 64:155-1561.

23) Riaz M, Zia-Ul-Haq M, Saad B (2016) Anthocyanins and Human Health: Biomolecular and therapeutic aspects. Springer Briefs in Food, Health, and Nutrition.

24) Nash LA, Sullivan PJ, Peters SJ, Ward WE (2015) Rooibos flavonoids, orientin, and luteolin, stimulate mineralization in human osteoblasts through the Wnt pathway. Mol. Nutr. Food Res 59:443-453.

25) Dhar U, Singh UK, Uddin A (2003) Ethanobotany of Bhuyans and Juangs of Orrisa. Medicinal Plants 7:200.

26) Warrier PK, Nambiar VPK, Ramankutty C (2003) Indian Medicinal Plants; A compendium of 500 species. Orient Longman 1:368-372.

27) Sharma B, Kumar P (2009) Extraction and pharmacological evaluation of some extracts of Tridax procumbens and Capparis deciduas. International Journal of Applied Research in Natural Products 1:5-12.

28) Mamun MA, Islam K, Alam MJ, Khatun A, Alam MM, et al. (2015) Flavonoids Isolated from Tridax procumbens (TPF) Inhibit Osteoclasts Differentiation and Bone Resorption. Biol Res 48:51.
Bari MA (2015) Tridax procumbens Flavonoids Promote Osteoblast Differentiation and Bone Formation. Biol Res 48:56.

30) Mamun MA, Hosen MJ, Khatun A, Alam MM, Al Bari MA (2017) Tridax procumbens Flavonoids: A Prospective Bioactive Compound Increased Osteoblast Differentiation and Trabecular Bone Formation. Biol Res 8;50:28.

31) Gulshan R, Sarwar MT, Mamun MA, Alam MJ, Hossain S, Alam MM (2013) Comparative study of antibacterial activity of vancomycin and chemically treated chitosan prepared from shrimp (Macrobrachium rosenbergii) waste. Int. J, Nutrition and Food Scie 2:307-311.

32) Nakamura $Y$, Tensho K, Nakaya $H$, Nawata M, Okabe T, Wakitani S (2005) Low dose fibroblast growth factor-2 (FGF-2) enhances bone morphogenetic protein-2 (BMP-2)-induced ectopic bone formation in mice. Bone 36:399-407.

33) Kubota K, Iseki S, Kuroda S, Oida S, Iimura T, Duarte WR, et al. (2002) Synergistic effect of fibroblast growth factor-4 in ectopic bone formation induced by bone morphogenetic protein-2. Bone 31:465-471.

34) Toyoda H, Terai H, Sasaoka R, Oda K, Takaoka K (2005) Augmentation of bone morphogenetic protein-induced bone mass by local delivery of a prostaglandin E EP4 receptor agonist. Bone 37:555-562.

35) Miyai K, Yoneda M, Hasegawa U, Toita S, Izu Y, Hemmi H, et al. (2009) ANA deficiency enhances bone morphogenetic protein-induced ectopic bone formation via transcriptional events. J Biol Chem 284:10593-600.

\footnotetext{
Submit your manuscript to a JScholar journal and benefit from:

ฯ Convenient online submission

ฯ Rigorous peer review

q Immediate publication on acceptance

ब Open access: articles freely available online

I High visibility within the field

ๆ Better discount for your subsequent articles Submit your manuscript at http://www.jscholaronline.org/submit-manuscript.php
} 